Received:

30-I-2019

Accepted:

$12-11-2019$

Published Online:

18-II-2019

\title{
Management of a Child with Reactive Attachment Disorder in the Dental Clinical Setting: A Case Report
}

\section{Manejo de un niño con trastorno de apego reactivo en el entorno}

\author{
clínico dental: Reporte de un caso
}

Arturo Garrocho-Rangel DDS, PhD1; Hilda Romero-Huízar DDS1;

Socorro Ruiz-Rodríguez DDS, MS'; Nadia P. Campos-Lara DDS ${ }^{1}$;

Fernando Pozos-Guillén MD²; Amaury Pozos-Guillén DDS, PhD1

1. Pediatric Dentistry Postgraduate Program, Faculty of Dentistry, San Luis Potosi University, San Luis Potosí, SLP, México.

2. Medicine Program, Academic Multidisciplinary Unit, Zona Huasteca, San Luis Potosi University, Cd. Valles, SLP, México.

Correspondence to: Dr. Amaury Pozos Guillén - apozos@uasIp.mx

ABSTRACT: Reactive attachment disorder (RAD) is an early childhood mental health disease characterized by impaired social interactions and communication abilities, and neurological deficits in the child's developing brain. This disorder can significantly affect the pediatric patient's behavior in the dental setting. An uncooperative 9-yearold Mexican girl, who was residing in a temporary home, was referred by a general dental practitioner to the Postgraduate Pediatric Dental Clinic with her caretaker, requesting dental examination and treatment. The patient presented with a previous diagnosis of RAD with intellectual/social disability. With the psychiatrist's guidance, an exhaustive oral prophylaxis was carried out in the initial appointments, followed by diverse restorative treatments under the continuous application of behavioral management techniques. These restorative procedures included resin restorations and pit-fissure sealants, under local anesthesia and rubber-dam isolation, on the first four permanent molars. The entire treatment was completed in six weeks. The patient and her caretaker were provided with detailed educational and motivational strategies for improving the patient's oral hygiene, and they also received nutritional advice. For control reviews and the reinforcement of preventive habits, future appointments were carefully scheduled. An interdisciplinary pediatric collaboration between the dentist, nurse, and psychiatrist was fundamental for improving the patient's oral health and general welfare.

KEYWORDS: Childhood reactive attachment disorder; Dental management; Pediatric psychiatric disorders.

GARROCHO A., ROMERO H., RUIZ S., CAMPOS N., POZOS F., POZOS A., 2020: Management of a Child with Reactive Attachment Disorder in the Dental Clinical Setting: A Case Report .-ODOVTOS-Int. J. Dental Sc., 22-1 (January-April): 39-46.

ODOVTOS-Int. J. Dent. Sc. I No. 22-1: 39-46, 2020. ISSN: 2215-3411. 39 
RESUMEN: El trastorno de apego reactivo (RAD, por sus siglas en inglés) es una enfermedad de salud mental en la primera infancia caracterizada por interacciones sociales y capacidades de comunicación deterioradas y por déficits neurológicos en el cerebro en desarrollo del niño. Este trastorno puede afectar significativamente el comportamiento del paciente pediátrico en el entorno dental. Una niña mexicana de 9 años de edad, poco cooperadora, que residía en un hogar temporal, fue remitida a la Clínica de Odontología Pediátrica con su cuidadora, solicitando un examen y tratamiento dental. La paciente presentó un diagnóstico previo de RAD con discapacidad intelectual/ social. Con la orientación del Psiquiatra, se llevó a cabo una profilaxis oral exhaustiva en las citas iniciales, seguidas de diversos tratamientos de restauración bajo la aplicación continua de técnicas de manejo del comportamiento. Estos procedimientos de restauración incluyeron restauraciones de resina y selladores de fosas y fisuras, bajo anestesia local y aislamiento con dique de goma, en los primeros cuatro molares permanentes. Todo el tratamiento se completó en seis semanas. La paciente y su cuidadora recibieron estrategias educativas y motivacionales detalladas para mejorar la higiene oral y también recibieron asesoría nutricional. Para las revisiones de control y refuerzo de los hábitos preventivos, las citas posteriores se programaron cuidadosamente. Una colaboración pediátrica interdisciplinaria entre el dentista, la enfermera y el psiquiatra fue fundamental para mejorar la salud oral y el bienestar general del paciente.

PALABRAS CLAVE: Trastorno de apego reactivo infantil; Manejo dental; Trastornos psiquiátricos pediátricos.

\section{INTRODUCTION}

Pediatric psychiatric disorders, such as attachment disorders, are considered as significant contributors to the global burden of human suffering, as they impede normal education, social relationships and the development of self-worth. Deeply emotionally disturbed children and adolescents with associated significant levels of dental anxiety require individual behavior management during dental treatment (1-3).

According to the Diagnostic and Statistical Manual of Mental Disorders (DSM-5) published by the American Psychiatric Association, 4 attachment disorders result from inadequate caregiving environments, present mainly in institutionalized young children (4-6). Attachment disorders encompass two clinical subtypes, the inhibited and disinhibited types $(5,7)$. In the inhibited type (Reactive Attachment Disorder or RAD), children tend to be emotionally withdrawn and unlikely to seek comfort or attention, even from parents, relatives, or caregivers. In the disinhibited type (Disinhibited Social Engagement Disorder or DSED), children are likely to be overly assertive in their social interactions, demanding attention or affection from any adult (including strangers) in their proximity (8).

Specifically, RAD is defined as a "pattern of markedly disturbed and developmentally inappropriate attachment behaviors, in which a child rarely or minimally turns preferentially to an attachment figure for comfort, support, protection and nurturance" $(4,9)$. It is considered as an early childhood mental health disease characterized by a neurological deficits in the child's developing 
brain, including extreme physiological stress, attention deficit with hyperactivity, impaired psychosocial interaction, difficulties in establishing an attachment relationship, poor emotional adaptation, deliberate manipulation of others, compulsive lying, and other notorious behavioral problems $(4,7,10)$. It is also very common that children exhibit a lack of remorse or guilt, and disinterest about performance in developmentally important activities (11). RAD usually begins before the age of 5 years and persists over time (10-12). It results from a lack of basic emotional attachment and/or pathogenic care conditions, particularly during the first years of childhood $(12,13)$. The disorder has also been strongly associated with early maltreatment and affects deprivation by the primary caregiver, typically through abuse, neglect, and abandonment $(4,7,14)$. Allen (15) mentions that RAD is currently considered essentially "the absence of a preferred attachment to anyone". A diagnostic requirement for this disorder is social neglect, which is the absence of adequate caregiving during childhood (13). In RAD children, psychological depression leads to increased levels of cortisol, inefficiencies in the functioning of serotonin and other neurotransmitters and reduced growth-hormone production (12,16). According to international epidemiologic data, RAD affects approximately $1-4 \%$ of children $(4,14)$, most of which (up to $30 \%$ ) are raised and live in institutions or temporary (foster) homes $(2,9,17)$.

The aim of the present report is to describe the challenging case of an uncooperative female pediatric patient previously diagnosed with RAD, who was dentally treated in our clinic employing continuous behavioral management procedures.

\section{CASE REPORT}

A 9-year-old Mexican girl, who was residing in a temporary home, was referred by a general dental practitioner to the Postgraduate Pediatric
Dental Clinic accompanied by her caretaker, requesting oral examination and treatment.

Medical history. The patient presented a previous diagnosis of reactive attachment disorder (RAD) with a significant intellectual/social disability. She had never previously received dental care. During questioning in the initial dental visit, the patient displayed an indifferent and emotionally distant attitude; she did not have any interest in forming a close relationship with the dental resident or the assistant personnel, and basic deficits in reasoning and judgment were evident. Furthermore, during the oral examination, an uncomfortable (manifested by moderate crying) and defiant/ belligerent behavior were noted, and the patient avoided all physical contact. The girl also exhibited difficulties to initiate or react to conversations with the dental team; however, she was able to understand and respond to simple commands.

An exhaustive general evaluation of the patient was performed, including past or present infectious diseases and a review of her immunization record. The following data were gathered from her medical record and caretaker: she was the product of a fourth pregnancy, born full term, with no complications; her birth weight and length were 2,200 $\mathrm{g}$ and $45 \mathrm{~cm}$, respectively. She was breastfed until 7 months of age and then weaned; her immunization record was complete.

Minimal health-related historical data about the patient could be collected. From birth to age 3 , her 19-year-old mother exhibited poor caregiving, which included inconsistent, permissive and punitive parenting, and the patient also experienced repeated emotional and physical abuse and neglect, including sexual abuse, and was exposed to chronic domestic violence. It was unknown if there were antecedents of maternal alcohol abuse during pregnancy. The girl did not remember her father, who was approximately 31 years old 
at the time of her birth, and she was unaware of the whereabouts of her three siblings. At age 3, she began living in two temporary homes, where she exhibited recurrent aggressive and significant emotional dysregulation, with rage episodes and other significant behavior problems. Finally, after evaluating her clinical presentation, diagnostic criteria, psychosocial history, comprehensive neurological, and psychiatric examinations, she was diagnosed with RAD-disinhibited type. Since that time, the patient had been under close psychiatric supervision and medicated with valproate sodium, risperidone and methylphenidate.

General and extraoral examination. The patient was physically examined, revealing a good general health status. Her height was $132 \mathrm{~cm}$, and her weight was $32.8 \mathrm{~kg}$, which indicated an average global growth rate, according to the cross-sectional growth chart for Mexican children. Except for her thinning hair, there was no evidence of abnormal extraoral signs in her skull, face, lips, and ears.

Intraoral examination. The patient's oral cavity exhibited an almost completely erupted mixed dentition, good-shaped dental arches with a very mild incisor crowding, excessive plaque accumulation, and halitosis, indicating neglected oral health and hygiene procedures. The incisor labial faces exhibited white/yellow spots, likely due to enamel fluorosis (Figure 1). Shallow carious cavities were present in the first four permanent molars. The patient exhibited a mild fissured geographic tongue; however, gingiva, other soft tissues, and tonsils did not exhibit any abnormalities.

Dental treatment. Based on the child's oral and medical care needs, it was decided to manage the patient in an interdisciplinary manner, including the dental team, the psychiatric, and a pediatric nurse. The girl's caretaker agreed the proposed dental treatment plan through the signature of an informed consent form. Then, with the psychiatrist's approval and guidance, an indepth oral prophylaxis was carried out during the initial three appointments, in which the patient was continuously psychologically approached by the pediatric dental staff and the nurse. The restorative procedures included several resin restorations and pit-fissure sealants, under local anesthesia and rubber-dam isolation, on the first four permanent molars. Fluoride varnishes were also applied. The entire treatment was completed in six weeks (Figure 2). Regarding the girl's behavior on the dental chair, she became fairly cooperative with some crying episodes and occasional arm movements towards her mouth, interrupting briefly the implementation of dental procedures. Once the restorative treatment finished, the patient and her caretaker were provided with detailed educational and motivational long-term strategies for improving her oral hygiene at home on a daily basis; they also received nutritional advice. For control reviews and the reinforcement of preventive habits, future appointments were carefully scheduled. No additional oral anomalies were found in the last visit. 

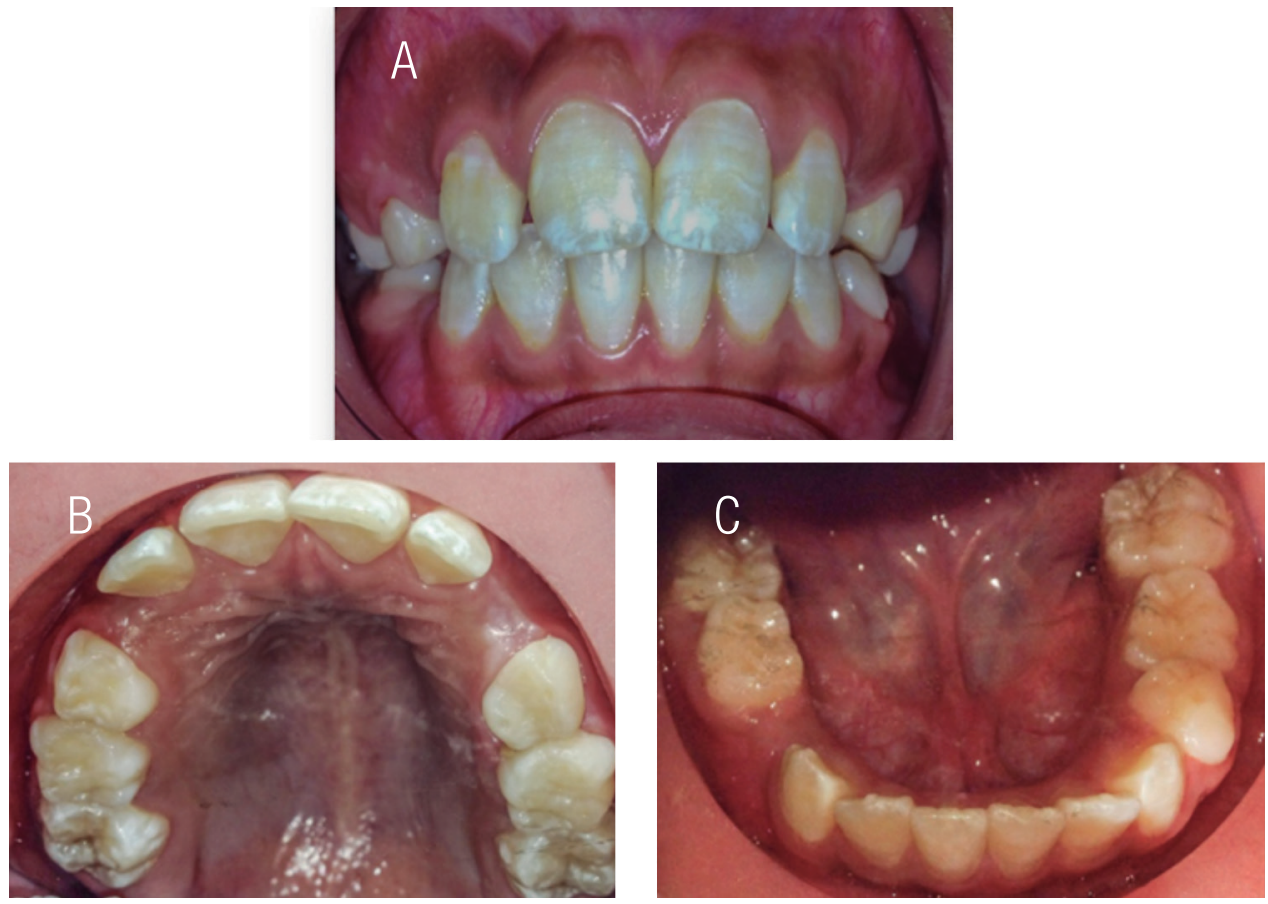

Figure 1. Initial views. (a) Intraoral frontal view; (b) Intraoral view of the maxillary arch; (c) Intraoral view of the mandibular arch.
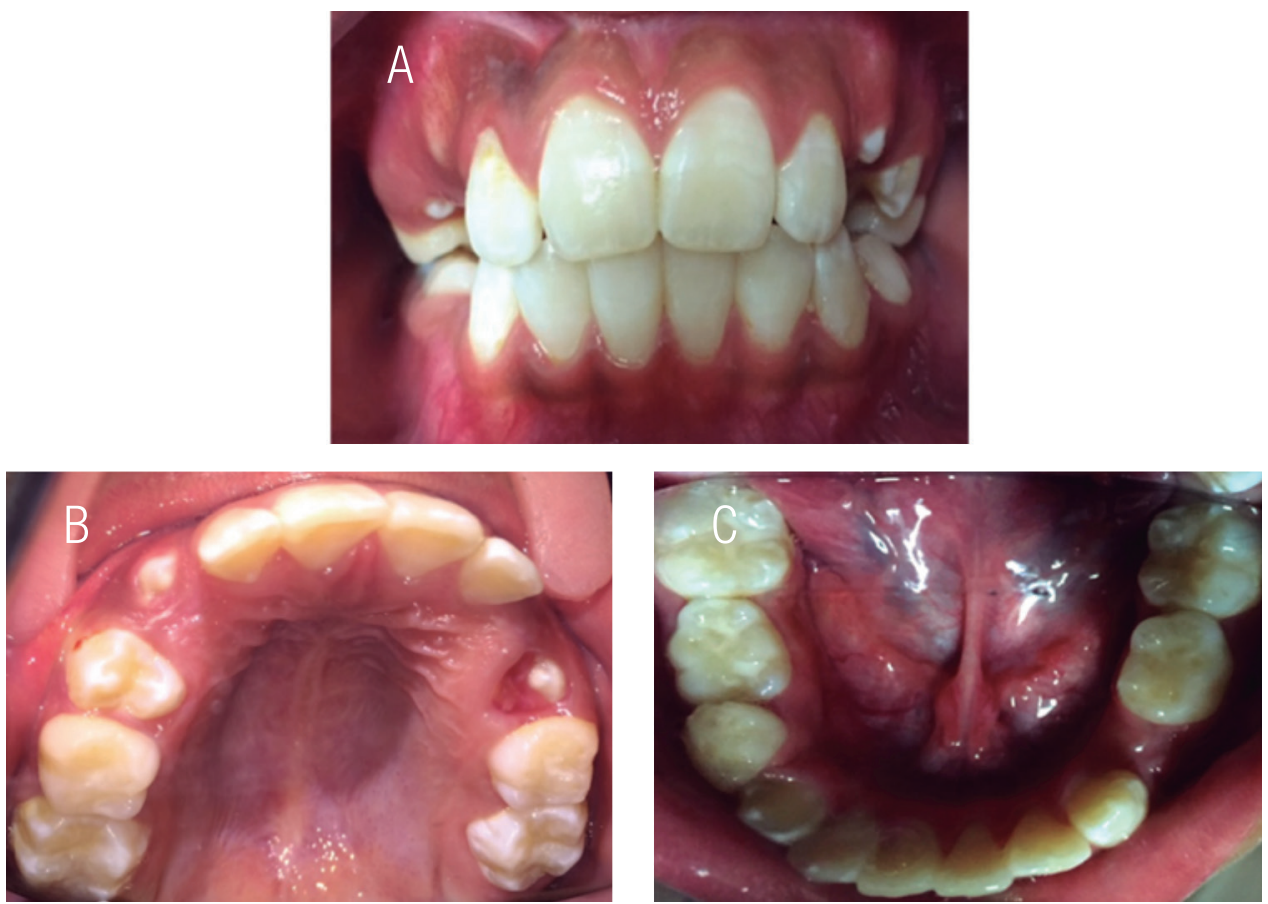

Figure 2. After treatment. (a) Intraoral frontal view; (b) Intraoral view of the maxillary arch; (c) Intraoral view of the mandibular arch. 


\section{DISCUSSION}

School-age children exhibiting RAD are more likely to present complex neurodevelopmental problems. Therefore, an opportune diagnosis, according to the DSM-5 criteria (4), and a proper treatment are crucial because RAD has been associated with personality impairments in adolescence and early adulthood (18). The medical management of the disorder is fundamentally psychological (e.g. enhanced caregiving, promoting secure and healthy attachments, teaching of basic pragmatic skills to affected children, developing appropriate rules and realistic limits, and maintaining routines for increasing feelings of security, in a consistent and compassionate manner), and, in some cases, psychiatric with specific drugs $(4,5,7)$. In this regard, some authors suggest that signs of RAD tend to diminish once the child is placed in a more normative caregiving environment (5).

Children with RAD are considered some of the most vulnerable young people in society if their trajectory is not adequately modified (18). It has been reported that the lack of treatment for RAD during childhood may be associated with adults who are diagnosed with sociopathic, narcissistic, antisocial or borderline disorders $(11,12)$. These children often show no pattern to their coping strategies and, frequently, confusion and considerable apprehension, which is reflected in the child's inability to form a sound and enduring relationship with their primary health caregiver, such as the pediatric dentist $(17,19)$. These traits significantly affect conduct in the dental office, including poor interpersonal relationship, stress modulation and behavioral adaptation (8), which are typically manifested as excessive or unreasonable anxiety and, consequently, avoidance of dental examination or treatment. Thus, the early recognition of the disorder, etiologic or precipitating factors, management, and effective parenting guiding are reasonable knowledge expectations for all healthcare providers, including pediatric dentistry practitioners (16). As primary health providers, pediatric dentists have to be aware of and suspect a potential RAD child if they observe some of the mentioned conduct characteristics, based on a careful and discreet questioning to the patient and a thorough clinical history that includes a screening for possible abuse or neglect (9).

Due to the patient's age, her defiant/belligerent behavior and her poor cooperation level, we decided to introduce her to the dental equipment in a gentle but consistent stepwise manner. Tellshow-do, conditioning, distraction, direct visual contact, positive reinforcement, and continuous friendly verbal communication were very helpful approaches during the initial appointments. We also noted that it was important to kindly ask permission before touching her. Additionally and prior to the start of dental treatment, the patient visited the pediatric dental clinic before sitting on the dental chair, where she could observe another patients being treated. Simultaneously, the patient attended several times the children's playroom of our clinic, a pleasant psychological throughgame conditioning space; there, she received psychological aid for learning ways to regulate her emotions and cope with diverse dental phobias. Thus, she gradually became more confident and communicative, with a better acceptance of treatment in the clinical setting.

Based on our experience obtained from the present case, we can say that RAD children can be safely managed in a University Clinic or Dental Office by well-informed pediatric dentistry clinicians. It is essential that the practitioner understand the disease and be informed on the prescribed medications in each individual patient. Likewise, some professional advice given by the dentist to the patient's parents or caregiver is always a useful approach. Behavior management of pediatric patients with mental health disorders such as RAD is a particular challenge for the 
practitioner and requires a proper clinical evaluation and an adequate treatment plan (3). Concerning the patient described herein, when designing the treatment plan, pharmacological conscious sedation was initially considered; however, after the oral prophylaxis was given during the initial appointments, applying consistent and thoughtful psychological approaches, a reasonably cooperative behavior was achieved. Additionally, as previously mentioned, the helpful therapeutic assistance of the specialized trained personnel from the clinic playroom, together with the valuable nursing/psychiatric supervision, were remarkably important for providing a successful dental treatment in a more relaxed environment.

Herein, a very uncommon case of attachment disorder in a 9-year-old girl exhibiting deep emotional and communication problems is reported. By means of extensive verbal communication, rigorous and consistent behavioral management and the assistance of the clinic playroom, a more relaxed and successful dental treatment could be delivered. Furthermore, the interdisciplinary pediatric collaboration between the dentist, nurse, and psychiatrist was fundamental for improving the patient's health and welfare. On the other hand, the development of a secure, nurturing and reciprocal attachment between a child and her parents (or other caregivers) during early childhood is necessary for a normal psychosocial and emotional growth. Failure to accomplish this task can result in profound and sometimes irreversible effects on the child's later social development.16,19 Pediatric dentistry practitioners, like any other health sciences professional, must be proactive in the assessment and management of the affected patient and in guiding the parents on the care of the child. Thus, in their daily practice, they should remember and promote the statement that "effective parenting is the best preventive measure that could reduce the RAD incidence in young children" (19).
In addition to own a basic understanding of the disorder, it is indispensable to carry out a comprehensive oral and general evaluation of RAD affected children while planning the dental treatment. The pediatric dentistry practitioner should approach the affected children according to their individual behavioral health care and communication needs and bearing in mind the inability of these patients to respond adequately to the affection and diverse social situations. In this regard, the joint work between the pediatric dentist, nurse, and psychiatrist was fundamental for improving the oral and systemic health and welfare of the patient reported here.

\section{ACKNOWLEDGMENTS}

The PFCE-UASLP 2018 grant supported partially this report.

\section{CONFLICT OF INTEREST}

No conflict of interest

\section{REFERENCES}

1. Klingberg G., Broberg A. G. Dental fear/anxiety and dental behaviour management problems in children and adolescents: A review of prevalence and concomitant psychological factors. Int J Paediatr Dent. 2007; 17 (6): 391-406.

2. Pecora P. J., Jensen P. S., Romanelli L. H., Jackson L. J., Ortiz A. Mental health services for children placed in foster care: An overview of current challenges. Child Welfare. 2009; 88 (1): 5-26.

3. Joshi S. R., Pendyala G. S., Saraf V., Choudhari S., Mopagar V. A comprehensive oral and dental management of an epileptic and intellectually deteriorated adolescent. Dent Res J (Isfahan). 2013; 10 (4): 562-7.

4. American Psychiatric Association. In: The Diagnostic and Statistical Manual of Mental 
Disorders. 5th ed. Washington, DC: American Psychiatric Association, 2013.

5. Zeanah C. H., Gleason M. M. Annual Research Review: Attachment disorders in early childhood - Clinical presentation, causes, correlates, and treatment. J Child Psychol Psychiatry. 2015; 56 (3): 207-22.

6. Lehmann S., Breivik K., Heiervang E. R., Havik T., Havik O. E. Reactive attachment disorder and disinhibited social engagement disorder in school-aged foster children A confirmatory approach to dimensional measures. J Abnorm Child Psychol. 2016; 44 (3): 445-57.

7. Phelps R., Eisert D., Schulz S., Augustyn M. Attached to a diagnosis: The quandary of social deficits and reactive attachment disorder. J Dev Behav Pediatr. 2017; 38 (Suppl 1): S3-5.

8. Buckner J. D., Lopez C., Dunkel S., Joiner T. E. Jr. Behavior management training for the treatment of reactive attachment disorder. Child Maltreat. 2008; 13 (3): 289-97.

9. Hallas D., Herman N. G., Benichou L., Morales E. L., Touchette L. Management of a child with nutritional Rickets, multiple cavities, enamel hypoplasia, and reactive attachment disorder. J Pediatr Health Care. 2015; 29(3): 283-8.

10. 10. Corval R., Belsky J., Baptista J., Oliveira P., Mesquita A., Soares I. Inhibited attachment disordered behavior in institutionalized preschool children: Links with early and current relational experiences. Attach Hum Dev. 2017; 19 (6): 598-612.

11. Mayes S. D., Calhoun S. L., Waschbusch D. A., Breaux R. P., Baweja R. Reactive attachment/disinhibited social engagement disorders: Callous-unemotional traits and comorbid disorders. Res Dev Disabil. 2017; 63: 28-37.
12. Lehman J. J., Jegtvig S. K. Reactive attachment disorder: A preventable mental health disease. J Chiropr Med. 2004; 3 (2): 69-75.

13. Mayes S. D., Calhoun S. L., Waschbusch D. A., Baweja R. Autism and reactive attachment/ disinhibited social engagement disorders: Coconcurrence and differentiation. Clin Child Psychol Psychiatr. 2017; 22 (4): 620-31.

14. van Ijzendoorn M. H., Schuengel C., Bakermans-Kranenburg M. J., Lehman J. J., Jegtvig S. K. Disorganized attachment in early childhood: Meta-analysis of precursors, concomitants, and sequelae. Dev Psychopathol. 1999; 11 (2): 225-49.

15. Allen B. Misperceptions of reactive attachment disorder persist: Poor methods and unsupported conclusions. Res Develop Disab. 2018; 77: 24-9.

16. Weinberg H. A. Improved functioning in children diagnosed with reactive attachment disorder after SSRI therapy. J Can Acad Child Adolesc Psychiatry. 2010; 19 (1): 48-50.

17. Smyke A. T., Zeanah C. H., Gleason M. M., Drury S. S., Fox N. A., Nelson C. A., Guthrie D. A randomized controlled trial comparing foster care and institutional care for children with signs of reactive attachment disorder. Am J Psychiatry. 2012; 169 (5): 508-14.

18. Mirza K., Mwimba G., Pritchett R., Davidson C. Association between reactive attachment disorder/disinhibited social engagement disorder and emerging personality disorder: A feasibility study. ScientificWorldJournal. 2016; 2016: 5730104.

19. Arnrup K., Broberg A. G., Berggren U., Bodin L. Temperamental reactivity and negative emotionality in uncooperative children referred to specialized paediatric dentistry compared to children in ordinary dental care. Int J Paediatr Dent. 2007; 17 (6): 419-29. 